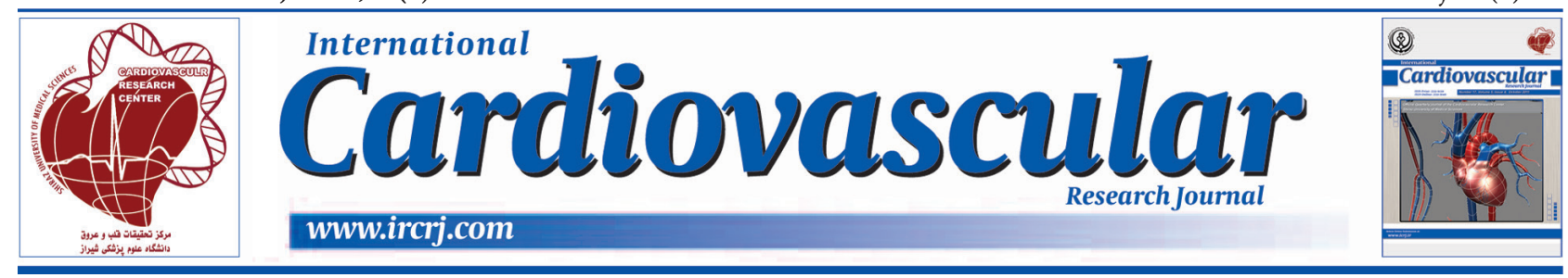

\title{
Cleft in the Anterior Mitral Valve Leaflet Assessed by Real-time 3D Echocardiography
}

\author{
Tahir Bezgin ${ }^{1,}{ }^{*}$, Cem Doğan ${ }^{1}$, Ali Karagöz ${ }^{1}$, Ali Elveran ${ }^{1}$, Cihangir Kaymaz ${ }^{1}$
}

${ }^{1}$ Kartal Koşuyolu Heart and Research Hospital, Cardiology Clinic, Istanbul, Turkey

\begin{tabular}{ll}
\hline A R T I C L E I N F O & A B S T R A C T \\
$\begin{array}{l}\text { Article Type: } \\
\text { Case Report }\end{array}$ & $\begin{array}{l}\text { Cleft in the anterior mitral leaflet is an infrequent congenital anomaly most often } \\
\text { encountered in association with other congenital heart defects. The importance of the } \\
\text { lesion is that it is often a correctable cause of Mitral Regurgitation (MR). }\end{array}$ \\
\hline
\end{tabular}

Article History:

Received: 23 Jun 2014

Accepted: 25 Feb 2015

Keywords:

Mitral Valve

3D Echocardiography

Implication for health policy/practice/research/medical education:

This study demonstrated a rarely seen congenital mitral valve pathology with the help of both conventional and 3-dimensional echocardiography. This underlines the importance of novel imaging techniques (3-dimensional echocardiography) in diagnosis and management of mitral valve pathologies and makes readers familiar with this technique.

\section{Introduction}

Clefts in the mitral valve are typically repaired by means of direct suture and annuloplasty rather than replacement when surgery is indicated. Echocardiography is the first choice imaging modality in assessment of mitral valve pathologies, providing both anatomic and hemodynamic information. We, herein, reported a case of an isolated cleft of mitral valve in the anterior leaflet.

\section{Case Presentation}

An asymptomatic 22 year-old male was referred for evaluation of a soft pansystolic murmur audible at the apex. Electrocardiography (ECG) showed normal sinus rhythm. Besides, chest roentgenogram revealed a clear lung field and no cardiomegaly. Transthoracic echocardiography, which was performed to explain the cause of murmur, also showed both normal left ventricular dimensions and function. The number and insertion of the papillary muscles were normal. MR through the cleft was noted.

*Corresponding author: Tahir Bezgin, Kartal Koşuyolu Heart and Research Hospital Denizer Cad. Cevizli 34846, Kartal-İstanbul, Turkey, Tel: +905054424712, Fax: +90-2164596321,

E-mail:bezgintahir3@yahoo.com
The normal left atrial dimensions, low density of the spectral Doppler regurgitation envelope, small proportion of the area of the left atrium filled by regurgitant flow, and normal E-wave velocity of mitral inflow classified this as mild regurgitation. To better delineate the cleft, $2 \mathrm{D}$ and $3 \mathrm{D}$ Transesophageal Echocardiography (TEE) were performed that enabled precise visualization of the cleft in the anterior mitral valve leaflet. Color Doppler examination with 2D TEE demonstrated 2 different mitral regurgitation jets; an anteriorly directed jet caused by the midline cleft in the anterior leaflet and a smaller posterior one between both leaflets (Figures 1 and 2). There were no other cardiac anomalies known to accompany a mitral cleft, such as an atrioventricular septal defect. The mitral valve appeared to be trileaflet in structure with the cleft mimicking as a third commissure between the anterior leaflets.

\section{Discussion}

Cleft in the mitral leaflets is an infrequent congenital anomaly most often encountered in association with other congenital heart defects. The importance of the lesion is that it is often a correctable cause of MR. Most commonly, 


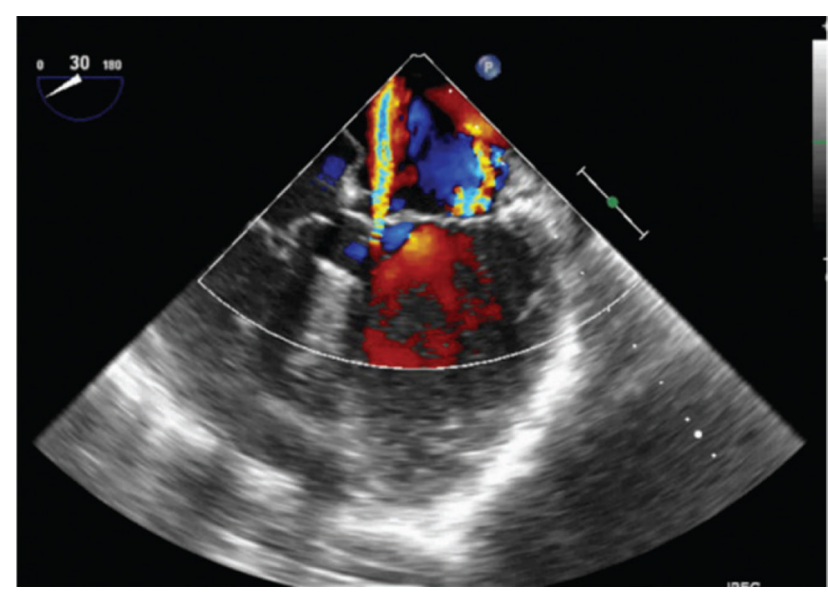

Figure 1. Anteriorly and Posteriorly Directed Jets Are Respectively Seen Through the Cleft of the Anterior Leaflet and between Both Leaflets of the Mitral Valve on Color Doppler

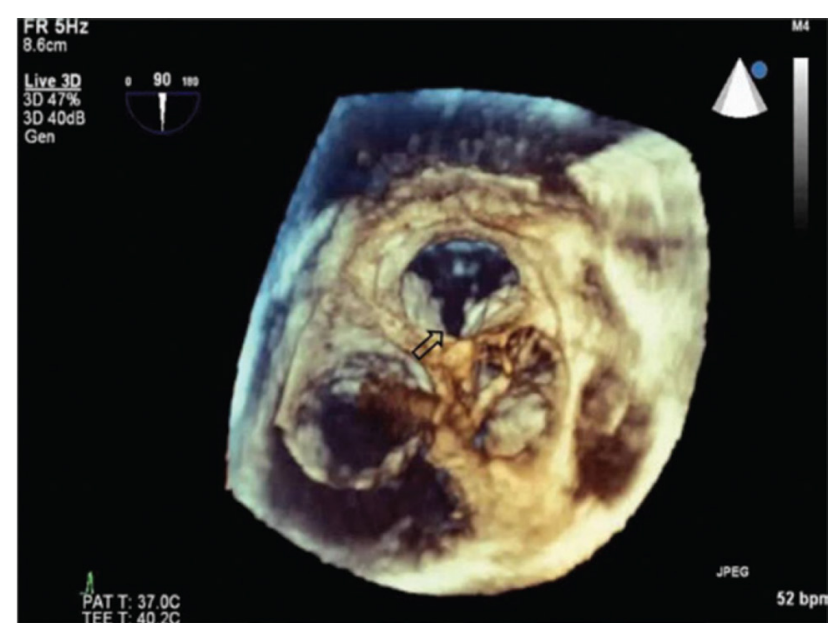

Figure 2. Cleft of the Anterior Mitral Valve Leaflet Seen on Three-dimensional Echocardiographic View (Arrow). The Cleft Is Seen from the Left Atrium. The Anterior Leaflet Is Bisected into Two Equal Parts.

the cleft involves the anterior leaflet of the mitral valve (1). It is seen as a part of an association involving defects in the Atrioventricular (AV) septum with the absence of a common AV junction, called left-sided AV valve cleft and mostly diagnosed in childhood. Less commonly, mitral clefts are encountered as an isolated abnormality of an otherwise morphologically normal mitral valve, referred to as the so-called isolated cleft mitral valve. Clefts in the posterior leaflet are rarely reported.

Echocardiography is the first choice imaging modality in assessment of suspected or known congenital abnormalities of mitral valve, ensuing useful data about anatomical and morphological details of mitral valve apparatus and mechanisms and quantitative evaluation of MR. Diagnosis of cleft can be difficult with conventional 2D echocardiography in some cases because of the position, dimensions, and shape of the lesion (2), and it may be detected for the first time during surgery for severe MR. 3D Echocardiography (3DE) can be useful in evaluation of these patients. 3DE provides assessment of mitral valve pathology precisely as it enables a comprehensive structural display in three dimensions from all perspectives. Its benefit in acquired and congenital mitral valve diseases has increasingly gained importance. Real Time 3D Echocardiography (RT3DE) is highly sensitive in diagnosis of cleft valves, providing detailed pathoanatomic definition, including size of the cleft, degree of fibrosis and edge retraction, presence of accessory chordae, and origin and mechanism of the regurgitant jet, in addition to characterizing the accompanying congenital malformations. RT3DE imaging also enables visualization of mitral valve en face either from the left atrium or left ventricle and provides a view of the valve similar to that seen intraoperatively by the cardiac surgeon (3). It has a further advantage of demonstrating the dynamic motion of the valve within the beating heart (4). Also, it may be helpful for planning the surgical strategy. Clinical presentation is variable and may be late in life, depending on the severity of MR and the associated cardiac lesions. Patients may be asymptomatic for years and mitral cleft may be found by chance if AV junction is intact and MR is mild (5-9).

As stated in our case, follow-up is a reasonable approach when patients have no symptoms and in the presence of trivial-to-mild regurgitation. MR is severe in half of patients. The otherwise normal mitral valve allows in general surgical correction with good mid-term results. Surgical repair, with direct suturing of the cleft edges or pericardial patch repair, is the technique of choice when MR is severe (10).

In our patient, imaging with real-time transesophageal 3DE had a complementary diagnostic value as it allowed more precise delineation of the mitral valve. Early recognition of this rare clinical entity and the co-existent anomalies can determine the affected patients who can be closely followed for symptom progression as well as ventricular dysfunction. Given the asymptomatic status of our patient and absence of ventricular dysfunction, it was decided to treat him conservatively with close clinical follow-up and periodic serial echocardiograms.

\subsection{Conclusion}

In comparison to $2 \mathrm{DE}, 3 \mathrm{DE}$ imaging is superior because it provides topographic details, such as the spatial location, width, and depth of the cleft, degree of fibrosis, disposition of accessory chordae or papillary muscles, and a virtual multiplanar perspective of associated congenital defects, which comprise invaluable data for preoperative surgical planning.

\section{Acknowledgements}

There is no acknowledgement.

\section{Authors' Contribution}

Study concept and design: Dogan, Bezgin. Analysis and interpretation of data: Karagoz, Kaymaz. Drafting of the manuscript: Bezgin. Critical revision of the manuscript for important intellectual content: Kaymaz, Elvearan

\section{Funding/Support}

There is no funding/support. 


\section{References}

1. Zegdi R, Amahzoune B, Ladjali M, Sleilaty G, Jouan J, Latremouille $\mathrm{C}$, et al. Congenital mitral valve regurgitation in adult patients. A rare, often misdiagnosed but repairable, valve disease. Eur $J$ Cardiothorac Surg. 2008;34(4):751-4.

2. Muratori M, Berti M, Doria E, Antona C, Alamanni F, Sisillo E, et al. Transesophageal echocardiography as predictor of mitral valve repair. J Heart Valve Dis. 2001;10(1):65-71.

3. Suri RM, Schaff HV, Dearani JA, Sundt TM, 3rd, Daly RC, Mullany CJ, et al. Survival advantage and improved durability of mitral repair for leaflet prolapse subsets in the current era. Ann Thorac Surg. 2006;82(3):819-26.

4. Schwartz SL, Cao QL, Azevedo J, Pandian NG. Simulation of intraoperative visualization of cardiac structures and study of dynamic surgical anatomy with real-time three-dimensional echocardiography. Am J Cardiol. 1994;73(7):501-7.
5. Amin A, Davis M, Auseon A. Isolated cleft posterior mitral valve leaflet: an uncommon cause of mitral regurgitation. Eur $J$ Echocardiogr. 2009;10(1):173-4.

6. Kent SM, Markwood TT, Vernalis MN, Tighe JF, Jr. Cleft posterior mitral valve leaflet associated with counterclockwise papillary muscle malrotation. J Am Soc Echocardiogr. 2001;14(4):303-4.

7. Kuhne M, Balmelli N, Tobler D, Linka A. Isolated cleft of the posterior mitral valve leaflet. Int J Cardiol. 2007;122(2):e15.

8. Mohammadi S, Bergeron S, Voisine P, Desaulniers D. Mitral valve cleft in both anterior and posterior leaflet: an extremely rare anomaly. Ann Thorac Surg. 2006;82(6):2287-9.

9. Toggweiler S, Hürlimann D, Grünenfelder J. Isolated posterior mitral valve cleft. Kardiovaskuläre Medizin. 2009;12(3):96-7.

10. Fraisse A, Massih TA, Kreitmann B, Metras D, Vouhe P, Sidi D, et al. Characteristics and management of cleft mitral valve. J Am Coll Cardiol. 2003;42(11):1988-93. 